\title{
Seasonal Clustering of Esophageal Atresia Cases at a Tertiary Care Neonatal Unit in South India
}

\author{
Ramesh B. Hatti ${ }^{1}$ (D) Anita Nyamagoudar ${ }^{2} \cdot$ Timman Gouda R. Patil $^{2} \cdot$ Sunil J. Patil ${ }^{2} \cdot$ Rajendra T. Patil $^{2}$. \\ Praveen Reddy Pylla ${ }^{3}$
}

Received: 21 January 2021 / Accepted: 16 March 2021 / Published online: 17 April 2021

(C) Dr. K C Chaudhuri Foundation 2021

To the Editor: The epidemiology of tracheaesophageal atresia/ esophageal atresia (TEF/EA) cases has reported prevalence of about 2.44 per 1000 live births from 18 birth cohorts [1]. However, its cyclic variation has scarcely been reported. This article highlights the geographical clustering with additional seasonal variation over the last four years (January 2016 to December 2019).

The study was conducted at Shanti Hospital, Bagalkot, a district headquarters in northern Karnataka, which is well equipped with pediatric surgical and critical care services, receiving regular referrals for the same.

Interestingly, there were four clusters of occurrence of TEF/ EA with a total of 69 cases with a survival rate of $79 \%$ among the operated cases. In the year 2016 and 2018, 12 and 8 cases were admitted over $66 \mathrm{~d}$ and $48 \mathrm{~d}$, respectively (in the months of August and September). In the year 2017 and 2019, there were 9 and 7 cases admitted over 52 and $32 \mathrm{~d}$, respectively (March and April). Thus, with alternate year, there was periodic clustering, as though cycling the pattern of occurrence. A geographical heat map revealed two hotspots in the northern part of the district—Jamkhandi and Mudhol (Taluka places).

Studies from Lucknow (UP) and Dharwad (North Karnataka) have shown single centered statistics of 127 and 54 cases over a period of 2 and $7 \mathrm{y}$, respectively [2, 3]. In the present study, only the 2018 cluster of TEF/EA was associated with clustering of infantile hypertrophic pyloric stenosis (IHPS).

Ramesh B. Hatti

docrbh@yahoo.co.in

1 Department of Pediatric Surgery, Shanti Hospital, 166A/1A Near Old IB, Extension Area, Bagalkot, Karnataka 587101, India

2 Department of Pediatrics and Neonatology, Shanti Hospital, Bagalkot, Karnataka, India

3 Department of Pediatrics, Shanti Hospital, Bagalkot, Karnataka, India
Felix et al. [4] showed association between contact with herbicides and occurrence of TEF/EA. In the present study, $90 \%$ of the cohort were farmers and $64 \%$ of the marriages were consanguineous in nature.

The geographic and seasonal clustering of TEF/EA cases over time and its association with various environmental/ genetic factors remains hypothetical at this time and remains to be an ongoing study at our center.

Acknowledgments Mr. Arun Bewoor for technical assistance.

\section{Declarations}

Ethical Committee Clearance Permission Number: SHA/2020/02/01 Date: 01/02/2020.

Conflict of Interest None.

\section{References}

1. Pedersen RN, Calzolari E, Husby S. Garne E; EUROCAT Working group. Oesophageal atresia: prevalence, prenatal diagnosis and associated anomalies in 23 European regions. Arch Dis Child. 2012;97(3):227-32.

2. Tandon RK, Sharma S, Sinha SK, et al. Esophageal atresia: factors influencing survival experience at an Indian tertiary centre. J Indian Assoc Pediatr Surg. 2008;13(1):2-6.

3. Gadgade BD, Annigeri VM, Kabbin G, Halgeri A. Outcomes of esophageal atresia in a tier II referral centre. Int Surg J. 2016;3(1): 318-20.

4. Felix JF, van Dooren MF, Klaassens M, Hop WCJ, Torfs CP, Tibboel D. Environmental factors in the etiology of esophageal atresia and congenital diaphragmatic hernia: results of a case-control study. Birth defects research part A: Clin Mol Teratol. 2008;82(2): 98-105. https://doi.org/10.1002/bdra.20423.

Publisher's Note Springer Nature remains neutral with regard to jurisdictional claims in published maps and institutional affiliations. 